\title{
PRELIMINARY ANALYSIS FOR AUTOMATIC TIDAL INLETS MAPPING USING GOOGLE EARTH ENGINE
}

\author{
J. A. Sartori ${ }^{1,}$, J. B. Sbruzzi ${ }^{2}$, E. L. Fonseca ${ }^{3}$ \\ ${ }^{1}$ Laboratório de Geotecnologias Aplicadas, Dept. of Geography, Geosciences Institute, Universidade Federal do Rio Grande do Sul, \\ Porto Alegre, Brazil - juliasartori_@ hotmail.com \\ ${ }^{2}$ Remote Sensing Graduate Program, Universidade Federal do Rio Grande do Sul, Brazil - janu.sbr@gmail.com \\ ${ }^{3}$ Laboratório de Geotecnologias Aplicadas, Dept. of Geography, Geosciences Institute, Universidade Federal do Rio Grande do Sul, \\ Porto Alegre, Brazil - eliana.fonseca@ufrgs.br
}

KEY WORDS: Lagoon, Shoreline change, Morphodynamics, Lagoa do Peixe

\begin{abstract}
:
This work aims to define the basic parameters for the automatic mapping of the channel between the Lagoa do Peixe and the Atlantic Ocean, which is located in the municipalities of Tavares and Mostardas, Rio Grande do Sul state, Brazil. The automatic mapping is based on an unsupervised classification of Landsat 8 satellite images at the Google Earth Engine cloud computing platform. The images used were selected to present both channel situations (opened and closed). Three images were selected with acquisition dates that presented the open channel and three that presented the closed channel. Each image was classified using the K-means clustering method, using separately band 6, band 7 (both located at shortwave infrared - SWIR) and the Normalized Difference Water Index (NDWI). Once the number of clusters must be defined a priori by the analyst, as well as the training sample area, these parameters were tested over the dataset and clustering results were compared. All of the generated clusters maps were analyzed over 10 random points, identifying the clustering hits and errors. Due to the absence of reference maps, all the final clustering maps for each date were compared with the composite true color image from the same acquisition date. The NDWI cluster maps showed the best results in separating water and non-water pixels.
\end{abstract}

\section{INTRODUCTION}

Lagoa do Peixe is a coastal lagoon located on the middle coast of Rio Grande do Sul state - Brazil, between Lagoa dos Patos and the Atlantic Ocean. Coastal lagoons are shallow water bodies, usually parallel to the coast, separated from the ocean by a barrier of sediments, but linked to the ocean, at least temporarily, by one or more channels (Kjerfve, 1994). Due to its shallow water and its high productivity, the Lagoa do Peixe is an important place for feeding, resting and breeding of migratory birds in South America. This is one of the main reasons for the creation of the Lagoa do Peixe National Park (LPNP) in 1986. A Brazilian National Park is a conservation modality that generated numerous conflicts with the farmers inserted there, since it prohibits housing and direct human interference in the area, such as fishing, livestock and agriculture. However, despite the National Park creation, the human activities within the park continue until now (Almudi, Kalikoski, 2009).

The Lagoa do Peixe presents a temporary connection with the Atlantic Ocean, which is rarely open by a natural way. The tidal inlets occurred only in years with positive anomalous precipitation, pattern that can be observed in this region during El Niño years. During the winter months, when the rainfall is relatively higher and the evaporation is relatively lower in the LPNP, when compared with the other seasons, the areas for cropping and grazing are flooded and local farmers demand the mechanical open of the channel to the Tavares City Hall. These procedures to open the channel aim both the water flow from lagoon to the sea, which allow the farm areas to dry, and the water flow from the sea to the lagoon, also allowing the shrimp larvae entrance in the lagoon. However, during the spring and summer months, due to the direction of the prevailing North and Northeast winds, the sand is again deposited on the spot, naturally closing the channel (Tomazelli, 1993).

This work aims to define the basic parameters for the automatic mapping of the channel between the Lagoa do Peixe and the Atlantic Ocean based on an unsupervised classification of Landsat satellite images using the Google Earth Engine cloud computing platform.

\section{STUDY AREA}

The Lagoa do Peixe National Park is located in the municipalities of Tavares and Mostardas, Rio Grande do Sul state, Brazil (Figure 1A and 1B). The classification procedures were performed in an area of 4 square kilometers, centered at the channel (Figure 1C).

According to the Köppen classification, the climate is classified as Cfa, which means humid subtropical climate with no dry season and with hot summer. The mean annual air temperature is $17.5^{\circ} \mathrm{C}$ and the annual total rainfall range goes from 1150 to $1450 \mathrm{~mm}$ (Alvares et al., 2014). The North and Northeast winds are the predominant in this region and determine, together with other factors, the orientation of the local barchans dunes, composed mainly of unconsolidated quartz sands (Tomazelli, 1993). The lagoon surroundings has vegetated banks (Figure 2), and the cultivation of the exotic species Pinus sp. on its east bank intended for forestry (Scottá et al., 2015).

\footnotetext{
* Corresponding author
} 




Figure 1. Study area situation map (A), the Lagoa do Peixe National Park border (red line) (B) and the Lagoa do Peixe channel (C).

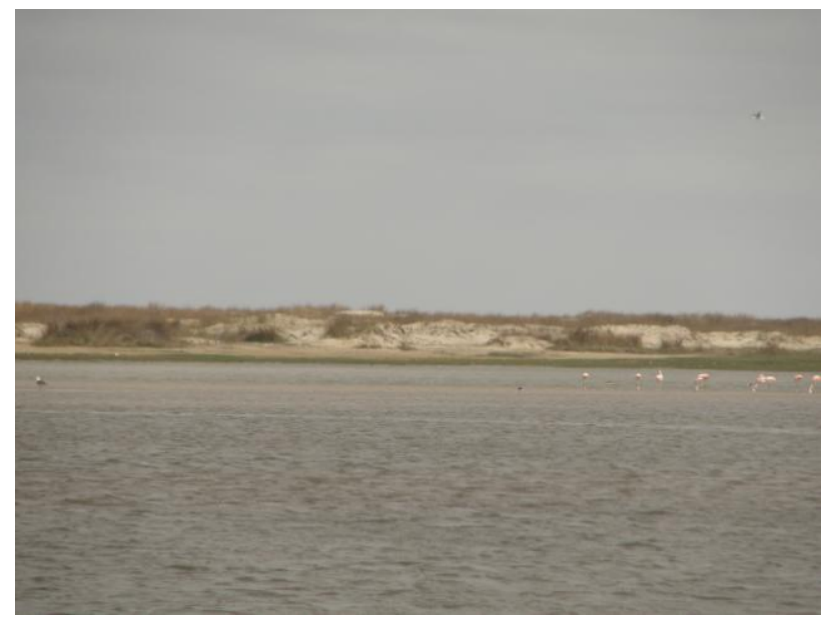

Figure 2. Landscape of the Lagoa do Peixe channel, where there can be noticed the migrant birds (flamingos) and the surroundings with vegetated banks.

\section{MATERIAL AND METHODS}

\subsection{Dataset}

The analysis was made at the Google Earth Engine cloud computing platform (Gorelick et al., 2017), with Landsat 8/OLI sensor imagery, with Top of Atmosphere Reflectance, available at the LANDSAT/LC08/C01/T1_TOA product, path/row $220 / 082$ and $221 / 082$. The images used for the analysis were selected to present both channel situations (opened and closed). Three images were selected with acquisition dates that presented the open channel and three that presented the closed channel (Table 1), in which there were no cloud cover over the study area.

\begin{tabular}{|r|c|c|}
\hline Acquisition date & Channel situation & ID \\
\hline $08 / 30 / 2013$ & Closed & $\mathrm{A}$ \\
$12 / 04 / 2013$ & Open & $\mathrm{B}$ \\
$01 / 05 / 2014$ & Open & $\mathrm{C}$ \\
$07 / 16 / 2014$ & Closed & $\mathrm{D}$ \\
$06 / 15 / 2017$ & Closed & $\mathrm{E}$ \\
$12 / 15 / 2017$ & Open & $\mathrm{F}$ \\
\hline
\end{tabular}

Table 1. Acquisition dates, channel situations and image identification (ID) for the analysis

Considering that the water reflectance is null at the infrared wavelengths (Jain, Singh, 2003), images were selected from the shortwave infrared (SWIR), namely band $6(1,566-1,651 \mathrm{~nm})$ and band $7(2,107-2,294 \mathrm{~nm})$ from the Landsat 8/OLI sensor for the classification procedure. These bands were selected based on the hypothesis that they would allow a better separation from water and sand dunes, which present a higher reflectance at SWIR (Jain, Singh, 2003).

The NDWI (Normalized Difference Water Index) is a satellite water based index that allows the separation of the water pixels from the other targets (McFeeters, 1996). These kinds of indices are widely used in ecological applications including surface water body characterization (Ma et al., 2019). The NDWI (Equation 1) is calculated from the green $(533-590 \mathrm{~nm})$ and near infrared (851-0.879 nm) wavelengths, namely band 3 and 5 from the Landsat 8/OLI sensor. The NDWI images were also used for the classification procedure.

$$
N D W I=(O L I 3-O L I 5) /(O L I 3+O L I 5)
$$

Where

$$
\begin{aligned}
& \text { OLI3 }=\text { green } \text { band } \\
& \text { OLI5 }=\text { near infrared band }
\end{aligned}
$$

\subsection{Classification procedures}

The classification approach used was the K-means clustering algorithm (MacQueen, 1967). K-means extracts regions from a satellite image using a minimum Euclidean distance decision rule. Each region is compared to the training dataset and is assigned to its closer cluster (Usman, 2013). The K-Means method was selected as it is an unsupervised image classification algorithm implemented at the GEE, since this preliminary analysis aims to establish parameters to automatically classify the entire historical series of Landsat images acquired over the Lagoa do Peixe channel. Once the number of clusters must be defined a priori by the analyst, as well as the training sample area, these parameters were tested over the dataset and clustering results were compared.

Due to the absence of reference maps, all the final clustering maps made with band 6, band 7 and NDWI, for each date, were compared with the composite color image (made with OLI bands 2, 3, 4, located at blue, green and red wavelengths) from the same acquisition date. By visual analysis, the generated clusters were analyzed over 10 random points (Figure 3), identifying the clustering hits and errors. 

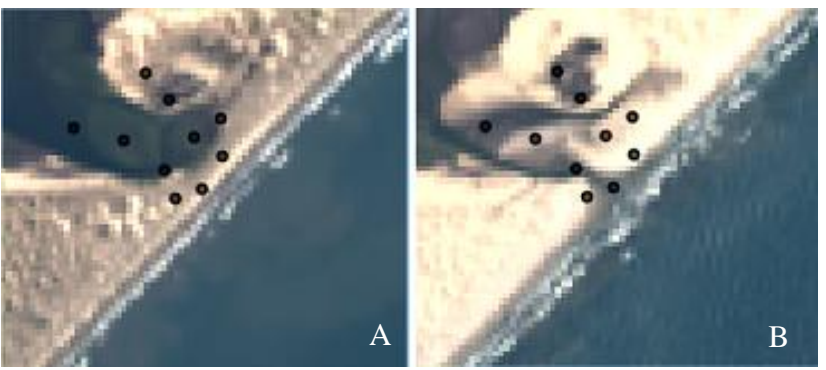

Figure 3. The points where the clustering maps were analyzed, over the color composite for the $08 / 03 / 2013$, closed (A), and $12 / 15 / 2017$, open channel (B) situations.

\section{RESULTS AND DISCUSSION}

\subsection{Parameters definition}

Since the channel presents various shapes for each analyzed year, as can be verified for each date by visual analysis, and considering that the training sample area must be the same for each image in order to allow the mapping of the entire image series with an automatic procedure, the best position for the sample area was established at Northwest in the study area (Figure 4). The training sample area, with an area around 0.12 square kilometers, presents pixels from two targets, with water and sand areas. In the GEE documentation no information was found about the "num pixels" parameter requested in the definition of the training sample area. Considering that this parameter can be related with the minimum pixels number to recognize a cluster, and considering the tests made with different values, the "num pixels" parameter was set to 20 .
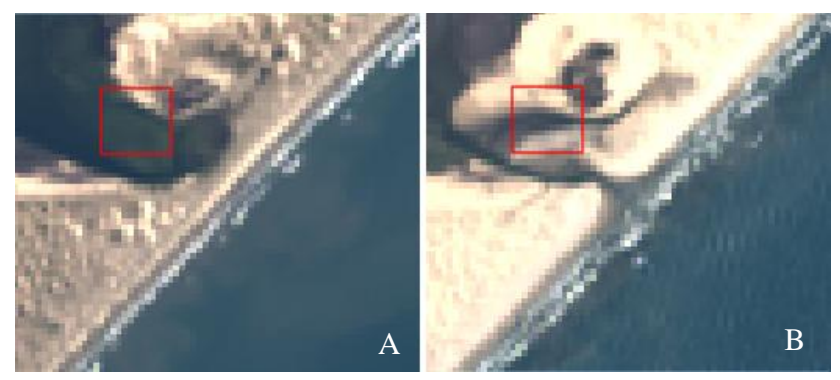

Figure 4 . The training sample area (red line) over the color composite for the $08 / 30 / 2013$, closed (A), and 12/15/2017, open channel (B) situations.

The number of clusters needed to be tested a few times until the best result was obtained. Ideally, the pixels would be binary clustered - such as 'water' and 'non-water'. In the cluster maps generated with the individual bands by this approach, a large portion of wet sand was grouped at the same cluster as the pure water pixels. Thus, the designation of three clusters made the algorithm separate the water pixels, sand pixels and a mixture of both in a third cluster. To the clustered maps generated with the NDWI, the two clusters definition allowed the water pixels and non-water pixels identification.

\subsection{Automatic mapping evaluation}

Despite the visual similarity between band 6 and band 7 images (Figure 5), the generated clusters maps are spatially different for these bands for all dates (Figure 6). The impossibility to generate only two clusters with the individual SWIR bands, which will require to the further analysis, was due to the wet sand class reflectance pattern. The wet sand class was the major error source, once the wet sand and the shallow water present a similar reflectance pattern, since the wetness decreases the soil reflectance and the shallow water reflectance is mixed with the background soil reflectance (Jain, Singh, 2003).

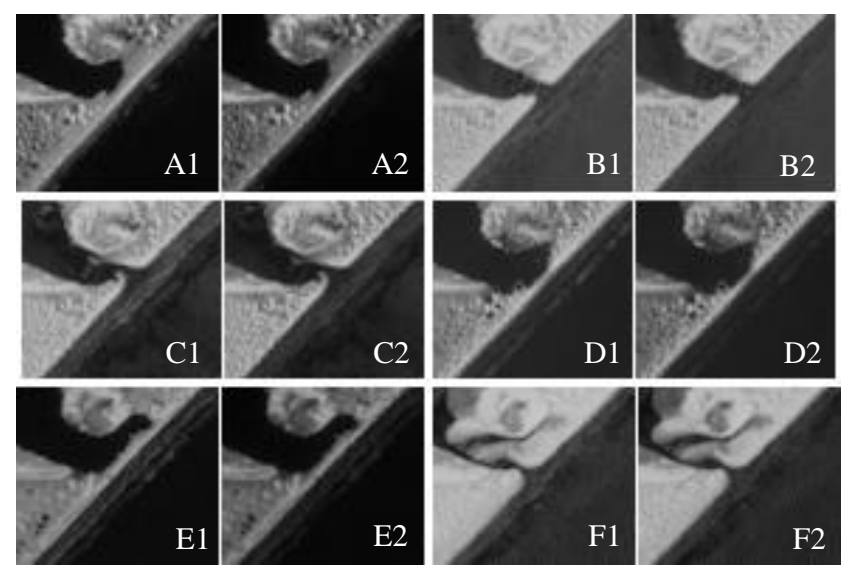

Figure 5. The band 6 (1) and band 7 (2) images for each analyzed date (A-F).

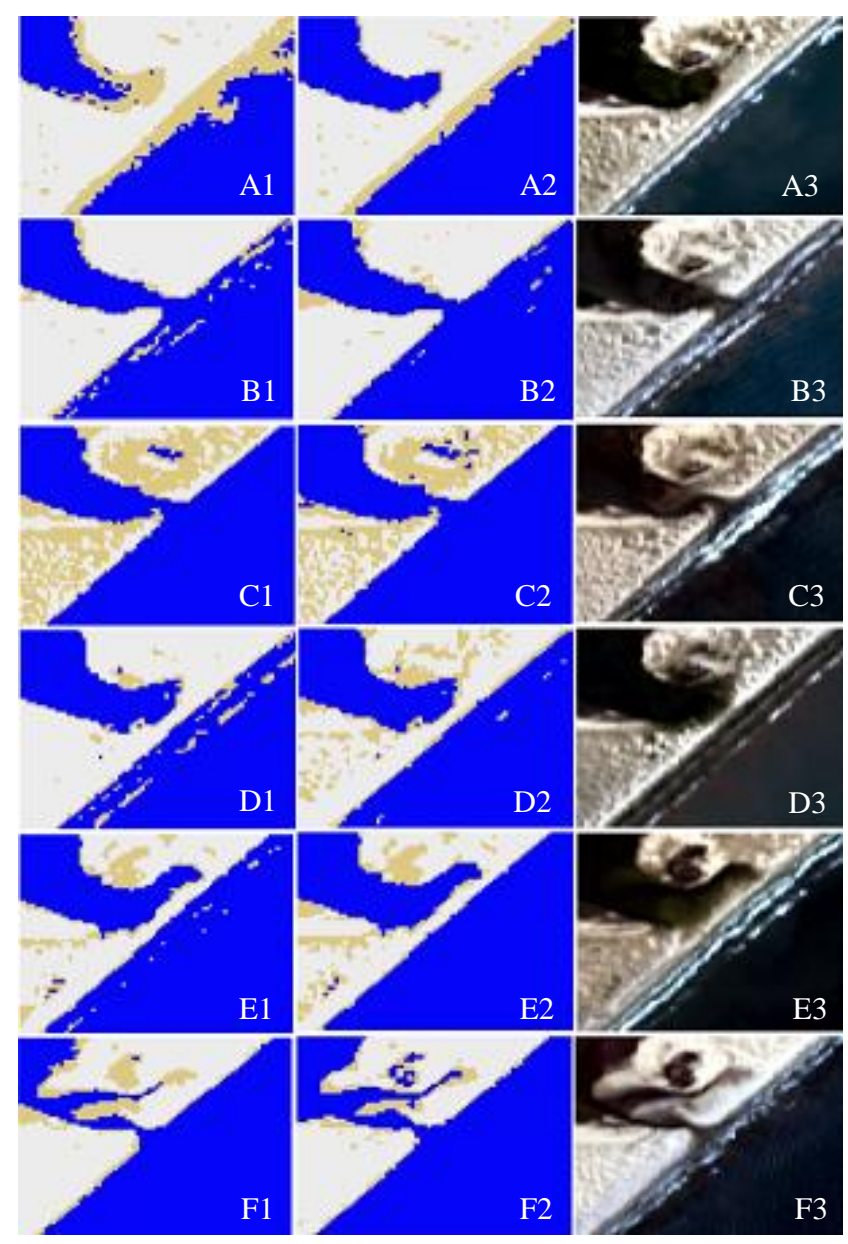

Figure 6. The clusters map for each date (A-F) for the band 6 (1) and band 7 (2), where the water is blue, the sand is white and the wet sand is brown, and composite color image (3). 
The cluster maps generated with the NDWI (Figure 7) show a better capacity of this index to map water and non-water classes than an only SWIR band, due to the green band values present at its equation (McFeeters, 1996), as can be seen by a visual analysis between NDWI images (Figure 7, index 1) and the generated maps (Figure 7, index 2).

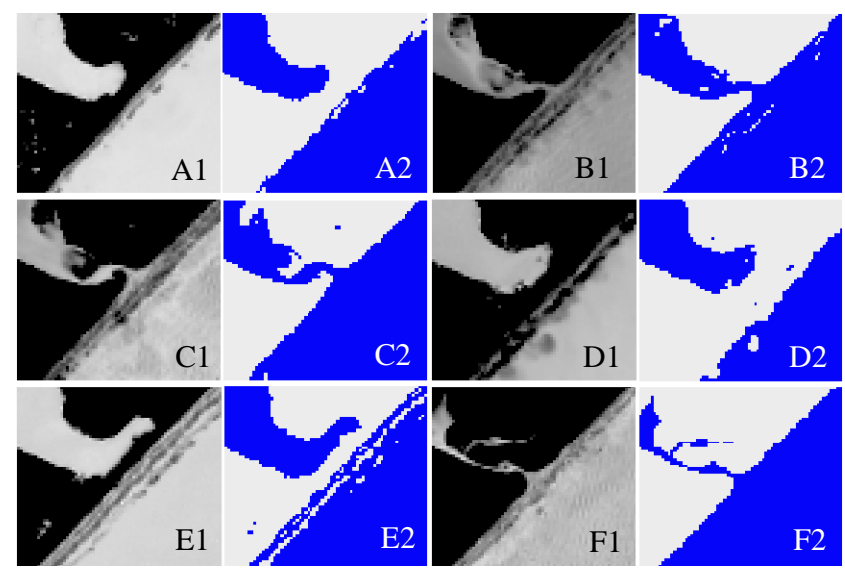

Figure 7. The NDWI (1) and cluster map (2) images for each analyzed date (A-F).

The Table 2 presents an accuracy evaluation considering the clustering hits and errors over 10 random points (Figure 3 ). According to this analysis, the NDWI capability to identify the water body's boundaries is evidenced by the high hits. The only date where the NDWI didn't reach $100 \%$ hits was 01/05/2014, probably due to a high precipitation event at this same day, before the image was acquired (around 30mm) (INMET, 2019). This high precipitation event promotes an accuracy decrease for all three cluster maps (Table 2), since the wetness alters the reflectance patterns in all electromagnetic spectrum bands (Jain, Singh, 2003).

\begin{tabular}{|c|c|c|}
\hline Acquisition date & Band & Hits (\%) \\
\hline $08 / 30 / 2013$ & band 6 & 80 \\
(A) & band 7 & 100 \\
& NDWI & 100 \\
$12 / 04 / 2013$ & band 6 & 80 \\
$(\mathrm{~B})$ & band 7 & 80 \\
& NDWI & 100 \\
$01 / 05 / 2014$ & band 6 & 60 \\
$(\mathrm{C})$ & band 7 & 60 \\
& NDWI & 90 \\
$07 / 16 / 2014$ & band 6 & 70 \\
$(\mathrm{D})$ & band 7 & 70 \\
& NDWI & 100 \\
$06 / 15 / 2017$ & band 6 & 80 \\
$(\mathrm{E})$ & band 7 & 80 \\
& NDWI & 100 \\
$12 / 15 / 2017$ & band 6 & 70 \\
$(\mathrm{~F})$ & band 7 & 70 \\
& NDWI & 100 \\
\hline
\end{tabular}

Table 2. Accuracy evaluation for clustering with band 6 , band 7 and NDWI for each analyzed date.

\section{CONCLUSIONS}

Based on the results, the NDWI calculated from Landsat 8 imagery, with two clusters, using always the same training sample area, were the best parameters set definition for the automatic mapping of the channel between the Lagoa do Peixe and the Atlantic Ocean, based on K-means algorithm to unsupervised classification procedures of satellite images, using the Google Earth Engine cloud computing platform.

\section{ACKNOWLEDGEMENTS}

To Universidade Federal do Rio Grande do Sul (UFRGS) for the Scientific Initiation Grant to the first author. To Coordenação de Aperfeiçoamento de Pessoal de Nível Superior (CAPES) for the Master Degree Grant to the second author.

\section{REFERENCES}

Almudi, T., Kalikoski, D. C., 2009: Homem e natureza em um Parque Nacional do Sul do Brasil: Meios de vida e conflitos nos arredores da Lagoa do Peixe. Desenvolvimento e Meio Ambiente, 20, 47-57. doi.org/10.5380/dma.v20i0.12291.

Alvares, C. A., Sentelha, P. C., De Moraes Gonçalves, J. L., Sparovek, G., 2014: Köppen's climate classification map for Brazil. Meteorologische Zeitschrift, 22(6), 711-728. doi.org/10.1127/0941-2948/2013/0507.

Gorelick, N., Hancher, M., Dixon, M., Ilyushchenko, S., Thau, D., Moore, R, 2017: Google Earth Engine: Planetary-scale geospatial analysis for everyone. Remote Sensing of Environment. 202, 18-27. doi.org/10.1016/j.rse.2017.06.031.

INMET, 2019: BDMEP - Banco de Dados Meteorológicos para Ensino e Pesquisa. bdmep.inmet.gov.br/ (27 October 2019).

Jain, S. K., Singh, V. P., 2003: Water Resources Systems Planning and Management, 51. Elsevier Science.

Kjerfve, B., 1994: Coastal Lagoon Processes. Elsevier Oceanography Series, 60, 1-8. doi.org/10.1016/S04229894(08)70006-0.

Ma, S., Zhou, Y., Gowda, P. H., Dong, J., Zhang, G., Kakani, V. G., Wagle, P., Chen, L., Flynn, K. C., Jiang, W., 2019: Application of the water-related spectral reflectance indices: A review. Ecological Indicators, 98, 68-79. doi.org/10.1016/j.ecolind.2018.10.049.

Macqueen, J. B., 1967: Some methods for classification and analysis of multivariate observations. Proceedings of the Fifth Berkeley Symposium on Mathematical Statistics and Probability. Berkley: University of California Press, Berkley. 1, 281-297.

McFeeters, S.K., 1996: The use of the Normalized Difference Water Index (NDWI) in the delineation of open water features. International Journal of Remote Sensing, 17(7), 1425-1432. doi.org/10.1080/01431169608948714.

Scottá, F. C., Rockett, G. C., Portz, L., Cardia, V. C., 2015: Deslocamento de dunas costeiras: Uma análise através de dados de sensoriamento remoto orbital na Lagoa do Peixe, RS. Gravel, 13(1), 15-25. 
The International Archives of the Photogrammetry, Remote Sensing and Spatial Information Sciences, Volume XLII-3/W12-2020, 2020 2020 IEEE Latin American GRSS \& ISPRS Remote Sensing Conference (LAGIRS 2020), 22-26 March 2020, Santiago, Chile

Tomazelli, L. J., 1993: O regime de ventos e a taxa de migração das dunas eólicas costeiras do Rio Grande do Sul, Brasil. Pesquisas. Porto Alegre: UFRGS, Instituto de Geociências, 20(1), 18-26. doi.org/10.22456/1807-9806.21278.

Usman, B., 2013: Satellite Imagery Land Cover Classification using K-Means Clustering Algorithm: Computer Vision for Environmental Information Extraction. Elixir Comp. Sci. \& Engg, 63, 18671-18675. 